\title{
Resveratrol inhibits the growth of gastric cancer via the Wnt/ $\beta$-catenin pathway
}

\author{
HUI DAI ${ }^{1}$, HOU-BO DENG ${ }^{2}$, YA-HONG WANG ${ }^{2}$ and JIA-JUAN GUO ${ }^{3}$ \\ ${ }^{1}$ Department of Tumor and Blood Disease; ${ }^{2}$ Department of Liver, Spleen and \\ Stomach Disease; ${ }^{3}$ Department of Cardiovascular Disease, Changchun University of \\ Traditional Chinese Medicine Affiliated Hospital, Changchun, Jilin 130021, P.R. China
}

Received June 22, 2017; Accepted October 6, 2017

DOI: $10.3892 / 01.2018 .8772$

\begin{abstract}
The inhibitory effect of resveratrol on the growth of gastric cancer cells through downregulation of the Wnt/ $\beta$-catenin signaling pathway were studied. First we determined the effective concentration of resveratrol on the growth and proliferation of MGC-803 gastric cancer cells. Methylthiazolyl tetrazolium assay showed that resveratrol significantly inhibited the proliferation of MGC-803 cells in a dose-dependent manner. Resveratrol induced apoptotic morphological changes in MGC-803 cells. Reverse transcription-polymerase chain reaction and western blot analysis showed that resveratrol downregulated the expression of three important components of the Wnt signaling pathway, $\beta$-catenin, c-myc, and cyclin D1, at the mRNA and protein levels. Overall, resveratrol inhibits the growth of MGC-803 cells by inhibiting the Wnt signaling pathway. This study provides a new idea and direction for the antitumor mechanism of resveratrol.
\end{abstract}

\section{Introduction}

At present, the death rate of gastric cancer is only second to lung cancer and its incidence ranks fourth in the world $(1,2)$. Clinical treatment for early gastric cancer is mainly focused on surgery. However, most patients are diagnosed at advanced stage when the treatment is more complicated. The main treatment method consists of chemotherapy comprehensive treatment. There is no standard chemotherapy strategy for advanced gastric cancer, a stage when chemotherapy cannot significantly improve survival. In addition, patients suffer adverse reactions caused by chemotherapy (3-5). As early

Correspondence to: Dr Jia-Juan Guo, Department of Cardiovascular Disease, Changchun University of Traditional Chinese Medicine Affiliated Hospital, 1478 Gongnong Road, Chaoyang, Changchun, Jilin 130021, P.R. China

E-mail: ue0202020@163.com

Key words: resveratrol, gastric cancer cells, Wnt/ $\beta$-catenin signaling pathway stages of gastric cancer have no characteristic features, it is often neglected. Some reports suggest that 50-60\% of patients are diagnosed with gastric cancer in middle or advanced stages in China. For confirmed patients, the resection rate is only $40 \%$. Given the high recurrence and metastasis after tumor resection, the prognosis is relatively poor. The 5 -year survival rate after surgery is only $20-30 \%$. Therefore, for patients in middle or advanced stages, especially those with local aggressiveness or metastasis, surgery alone is not the ideal treatment (6). Currently, the treatment for gastric cancer has shifted from simple surgery to combination with radiotherapy and chemotherapy, including target-specific treatments, like herceptin and other medicines (7).

Current clinical therapies often have serious adverse reactions, leading to severe pain and serious impact on the quality of life. Traditional Chinese medicine has many advantages, including high efficiency and low toxicity. These significant advantages have attracted recent interest from Chinese and Western researchers. A report suggested that the traditional Chinese extracts have relevant ability to inhibit cell proliferation, inducing apoptosis, reducing the adverse reaction to radiotherapy and chemotherapy (8). Resveratrol is a non-flavonoid polyphenol with wide pharmacological actions, including anti-mutation, antioxidative, and various biological activities and pharmacological actions. In previous years, the strong antitumor activity of resveratrol has attracted wide attention $(9,10)$.

Here, we report the inhibitory effect of resveratrol on the growth of MGC-803 gastric cancer cells and the involvement of the Wnt/ $\beta$-catenin pathway. These results lay the foundation for clinical treatment of gastric cancer with resveratrol.

\section{Materials and methods}

Materials and reagents. Resveratrol, methylthiazolyl tetrazolium (MTT) assay (both from Sigma; Merck KGaA, Darmstadt, Germany); MGC-803 gastric cancer cell line (Chinese Academy of Sciences Cell Bank, Shanghai, China); rabbit anti-human glyceraldehyde 3-phosphate dehydrogenase (GAPDH), $\beta$-catenin, c-myc, cyclin D1 polyclonal antibodies, and goat anti-rabbit HRP-conjugated secondary antibody (cat. nos. 10494-1-AP, 51067-2-AP, 10828-1-AP, 60186-1-Ig, SA00001-2; Wuhan Sanying Biotechnology, Wuhan, China); 
Dulbecco's modified Eagle's medium (DMEM) (Gibco; Thermo Fisher Scientific, Inc., Waltham, MA, USA); RNA extraction kits, reverse transcription kits, reverse transcriptionpolymerase chain reaction (RT-PCR) kits (all from Invitrogen; Thermo Fisher Scientific, Inc.); primer synthesis (Takara Biotechnology Co., Ltd., Dalian, China); bicinchoninic acid (BCA) protein excretion kits, cell lysis buffer (both from Beyotime Institute of Biotechnology, Nantong, China). The study was approved by the Ethics Committee of Changchun University of Traditional Chinese Medicine Affiliated Hospital (Changchun, China).

Cell culture. MGC-803 gastric cancer cells were cultured at $37^{\circ} \mathrm{C}$ and $5 \% \mathrm{CO}_{2}$. When cells reached $85 \%$ confluence, we trypsinized them, and added DMEM culture medium with $10 \%$ fetal bovine serum to dilute cell suspension. The cell concentration was adjusted to $2 \times 10^{8}$ cells $/ 1$. After counting, the cells were inoculated to the corresponding culture plates for the use of following experiments.

Inhibition of cell proliferation. A total of $100 \mu 1$ of cell suspension were inoculated into 96 well plates at $1 \times 10^{5}$ cells $/ \mathrm{ml}$. After $24 \mathrm{~h}$, resveratrol was added at final concentrations of $0,50,75$ and $100 \mu \mathrm{M}$. Each concentration was repeated in 5 wells and independently replicated 6 times. The control group receive no treatment. The cells were cultured at $37^{\circ} \mathrm{C} 5 \% \mathrm{CO}_{2}$ for 24 , 48 , and $72 \mathrm{~h}$, and then the solution was changed. A total of $10 \mu \mathrm{l}$ MTT was added into each well at $5 \mathrm{mg} / \mathrm{ml}$. After $4 \mathrm{~h}$, the optic density (OD) value at $570 \mathrm{~nm}$ was detected in each well. The proliferation inhibitory rate was calculated according to following formula: Inhibition rate $(\%)=(\mathrm{OD}$ in control group - OD in experimental group)/OD in control group x 100 .

Cytomorphology observation. When the culture of MGC-803 cells was ready, the cells were cultured with 50,75 , and $100 \mu \mathrm{M}$ resveratrol. The morphologic changes of each group were observed and filmed in an inverted microscope (Nikon Corp., Tokyo, Japan).

$R T-P C R$. MGC-803 cells were inoculated in a 6-well plate, each well containing $10^{4}$ cells. After $24 \mathrm{~h}$, the supernatant was discarded. The cells were then cultured with $0,50,75$, and $100 \mu \mathrm{M}$ resveratrol for $48 \mathrm{~h}$. After collecting the cells in each group, the total RNA was extracted according to the instructions in the RNA extraction kit. Concentration and purity of total RNA were detected by UV-Vis spectrophotometer (Hitachi, Ltd., Tokyo, Japan) (A260/A280 >1.8 is considered to be qualified). Then cDNA was produced by reverse transcription according to the instructions of the reverse transcription kits. Then the cDNA was used as template to determine the expression of $\beta$-catenin, c-myc and cyclin D1 mRNA according to the instructions on the RT-PCR kit. The primer sequences are shown in Table I. The reaction conditions were: $95^{\circ} \mathrm{C} 10 \mathrm{~min}$, $95^{\circ} \mathrm{C} 15 \mathrm{sec}, 60^{\circ} \mathrm{C} 1 \mathrm{~min}$, and 40 amplification circles. Cq value was obtained from instrument software. The relative expression was calculated by $2^{-\Delta \Delta \mathrm{Cq}}$ method according to following formula: $\Delta \mathrm{Cq}($ target gene $)=\mathrm{Cq}($ target gene $)-\mathrm{Cq}($ target gene $)$.

Western blot analysis. MGC-803 cells were inoculated in 6 -well plates, each well containing $10^{4}$ cells. After $24 \mathrm{~h}$, the
Table I. RT-PCR primer sequence.

\begin{tabular}{ll}
\hline Gene & \multicolumn{1}{c}{ Primer sequence } \\
\hline$\beta$-catenin & F: 5'-GCTTGGAATGAGACTGCTGA-3' \\
& R: 5'-CTGGCCATATCCACCAGAGT-3' \\
c-myc & F: 5'-AGCGACTCTGAGGAGGAACA-3' \\
& R: 5'-TCCAGCAGAAGGTGATCCA-3' \\
cyclin D1 & F: 5'-TGCCACAGATGTGAAGTTCATT-3' \\
& R: 5'-CAGTCCGGGTCACACTTGAT-3' \\
GAPDH & F: 5'-CAAGGTCATCCATGACAACTTTG-3' \\
& R: 5'-GTCCACCACCCTGTTGCTGTAG-3' \\
\hline
\end{tabular}

F, forward; R, reverse; GAPDH, glyceraldehyde 3-phosphate dehydrogenase; RT-PCR, reverse transcription-polymerase chain reaction.

supernatant was discarded. The cells were then cultured with $0,50,75$, and $100 \mu \mathrm{M}$ resveratrol for $48 \mathrm{~h}$. After collecting the cells in each group, they were treated with lysis buffer. Then the cells were centrifuged for $15 \mathrm{~min}$ at $4^{\circ} \mathrm{C}$ at low temperature and high speed, and the supernatant was collected. BCA kits were used to detect protein levels. A total of $50 \mu \mathrm{g}$ proteins were used for sodium dodecyl sulphate-polyacrylamide gel electrophoresis electrophoretic separation. The separated protein was electro-transferred into polyvinylidene fluoride film. The membranes were sealed for $1 \mathrm{~h}$ at room temperature with blocking buffer. Primary antibody was added for incubation $(1: 1,000)$ overnight at $4^{\circ} \mathrm{C}$. After fully washing the membrane with TTBS, the secondary antibody $(1: 2,000)$ was added for incubation for $1 \mathrm{~h}$ at room temperature. The signal was developed with ECL in a dark room and scanned by gel imaging (Bio-Rad Laboratories, Inc., Hercules, CA, USA). GADPH was used as internal reference for band quantitation.

Statistical analysis. Data were expressed as mean \pm standard deviation and processed by SPSS 17.0 (SPSS, Inc., Chicago, IL, USA). Data were analyzed by one-way ANOVA and the post hoc used was Least Significant Difference test. A P $<0.05$ was considered to indicate a statistically significant difference.

\section{Results}

Resveratrol inhibits the proliferation of MGC-803 cells. We first treated MGC-803 cells with 0, 50, 75, and $100 \mu \mathrm{M}$ resveratrol and measured proliferations at 24,48 , and $72 \mathrm{~h}$. Resveratrol significantly inhibited MGC- 803 cell proliferation in each group in a time- and dose-dependent manner $(\mathrm{P}<0.01)$ (Table II). Given the dose-dependent effects of resveratrol, we used 50,75, and $100 \mu \mathrm{M}$ resveratrol for the remaining experiments with an incubation time of $48 \mathrm{~h}$.

Effect of resveratrol on MGC-803 cell morphology. We next examined the morphology of MGC-803 cells after treatment with resveratrol. After $48 \mathrm{~h}$ culture with $0,50,75$ and $100 \mu \mathrm{M}$ resveratrol, the cell morphology significantly changed compared with the control group (Fig. 1). Cell shrinkage was 
Table II. Effect of resveratrol on the proliferation of MGC-803 cells.

\begin{tabular}{lccc}
\hline & \multicolumn{2}{c}{ Proliferation inhibition rate $(\%)$} \\
\cline { 2 - 4 } Concentration $(\mu \mathrm{M})$ & $24 \mathrm{~h}$ & $48 \mathrm{~h}$ & $72 \mathrm{~h}$ \\
\hline 0 & 0 & 0 & 0 \\
50 & $7.9 \pm 0.12^{\mathrm{a}}$ & $19.32 \pm 4.13^{\mathrm{a}}$ & $27.92 \pm 4.33^{\mathrm{a}}$ \\
75 & $13.4 \pm 0.31^{\mathrm{a}}$ & $33.32 \pm 2.31^{\mathrm{a}}$ & $39.25 \pm 5.12^{\mathrm{a}}$ \\
100 & $18.7 \pm 1.32^{\mathrm{a}}$ & $37.51 \pm 3.28^{\mathrm{a}}$ & $53.47 \pm 6.21^{\mathrm{a}}$ \\
\hline
\end{tabular}

Compared with the control group, ${ }^{\mathrm{a}} \mathrm{P}<0.01$.

\section{Resveratrol $(\mu \mathrm{M})$}

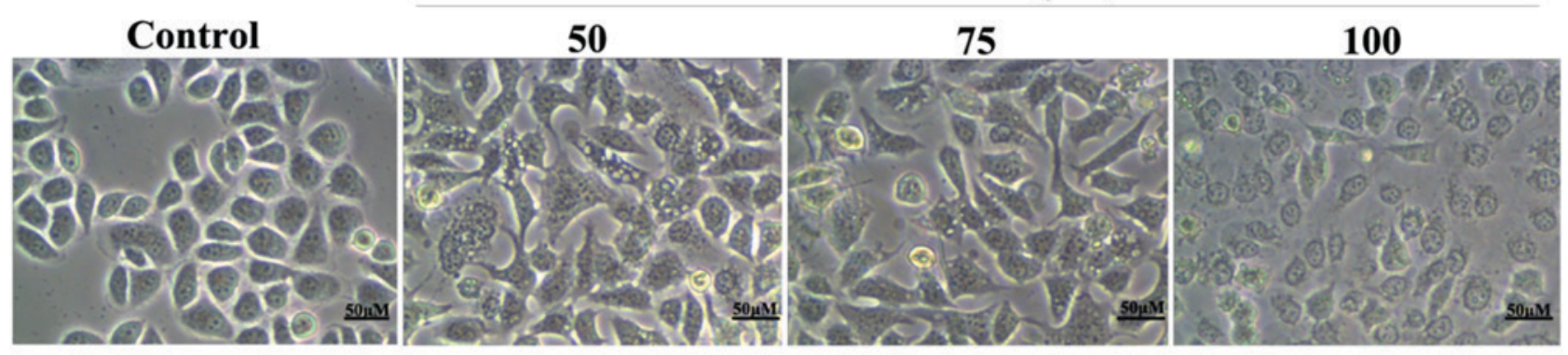

Figure 1. In the $48 \mathrm{~h}$ treatment with different concentrations of resveratrol, the effect on the MGC-803 cell morphology was observed under an inverted microscope.

observed and the adherence was not firm. The number of proliferating cells was lower with strong dose-dependence.

Resveratrol inhibits the expression of $\beta$-catenin, $c$-myc, and cyclin D1 mRNA. To try to understand mechanistically the effects of resveratrol, we examined the expression of proliferation markers: $\beta$-catenin, c-myc, and cyclin D1. After culturing MGC-803 cells for $48 \mathrm{~h}$ with $0,50,75$, and $100 \mu \mathrm{M}$ resveratrol, the levels of $\beta$-catenin, c-myc, and cyclin D1 mRNA were all significantly downregulated compared with the control group $(\mathrm{P}<0.01)$ (Fig. 2). In the three cases, we observed a dose-dependent response to resveratrol, suggesting its ability to downregulate the expression of these key cell proliferation targets.

Resveratrol inhibits the expression of $\beta$-catenin, $c$-myc and cyclin D1 proteins. To confirm the above results on mRNA levels of key proliferation genes, we next examined the proteins levels for the same three targets. Culturing MGC-803 cells for $48 \mathrm{~h}$ with $0,50,75$, and $100 \mu \mathrm{M}$ resveratrol, the levels of $\beta$-catenin, c-myc, and cyclin D1 proteins were significantly inhibited compared with the control group $(\mathrm{P}<0.01)$ (Fig. 3). These results also demonstrated dose-dependency.

\section{Discussion}

The incidence of gastric cancer in Asia and South Africa has been historically higher than that in the USA and West Europe. Though the incidence of gastric cancer has shown downward tendency globally since the 1950s, the current incidence keeps increasing (11). Chemotherapy is the main treatment methods, but has serious adverse actions and its cost often results in low treatment adherence. Therefore, it is essential to explore treatments featuring high effectiveness, low toxicity, and reasonable price. In previous years, China has dedicated increasing attention on the production and development of traditional Chinese medicine. In the field of tumor inhibition, molecular biology methods have been applied to improve the research level of traditional Chinese medicine and provided wider prospect for its application in clinical practice.

$\beta$-catenin is a membrane protein that promotes cell adhesion. When it translocates to the nucleus or is degraded, the adherent activity will disappear (12). Research suggest that $\beta$-catenin has both cell adhesion and signal transduction functions. The abnormal activation of the Wnt/ $\beta$-catenin signal pathway is one of the critical mechanisms of human tumorigenesis. $\beta$-catenin overexpression is the main manifestation of the activation of this signal pathway (13). The proto-oncogenes cyclin D1 and c-myc play important roles in cell proliferation, differentiation, and apoptosis, and are correlated with the incidence of many tumors. Interestingly, cyclin D1 and c-myc are important target genes in Wnt signal pathway (14). Immunohistochemical research has confirmed that the abnormal expression of cyclin D1, c-myc, $\beta$-catenin correlates with the activation of Wnt signal pathway in many tumors. When the Wnt signal pathway is activated, $\beta$-catenin enters into the nucleus, further activating the expression of cyclin D1 and c-myc genes promoting cell proliferation (15). Abnormal nuclear accumulation and activation of $\beta$-catenin becomes a tumorigenic gene. Research has proved that 
A

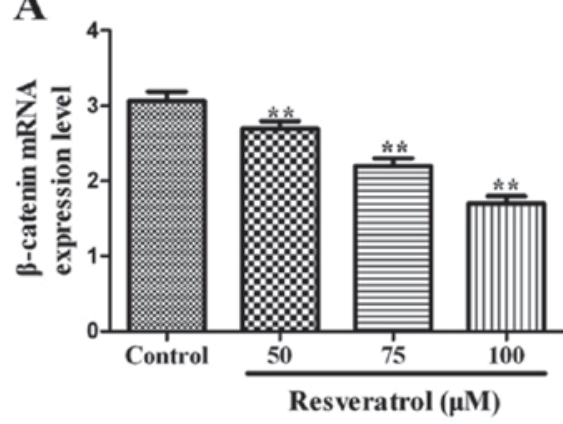

B

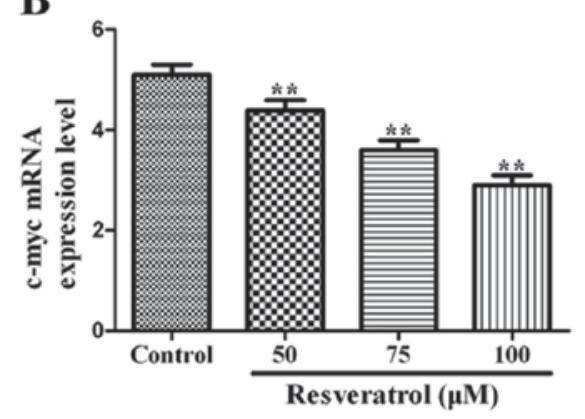

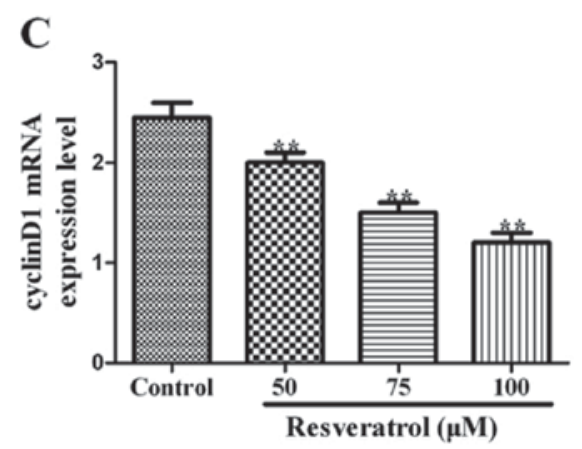

Figure 2. Resveratrol inhibits the expression of $\beta$-catenin, c-myc, and cyclin D1 mRNA in MGC-803 cells. Compared with the control group, the expression levels of $\beta$-catenin, c-myc and cyclin D1 in each group with different levels of resveratrol were significantly inhibited, ${ }^{* *} \mathrm{P}<0.01$.

A

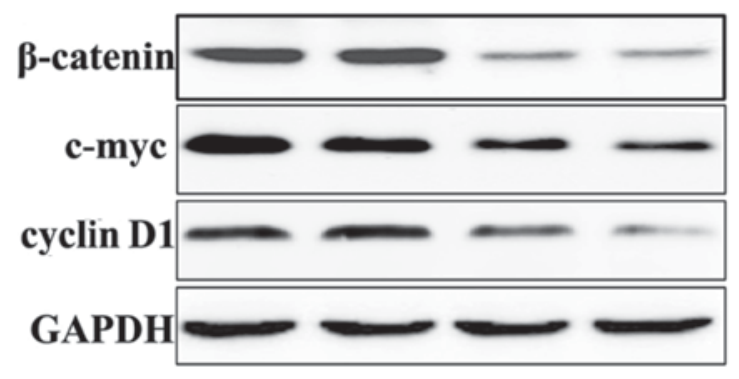

B

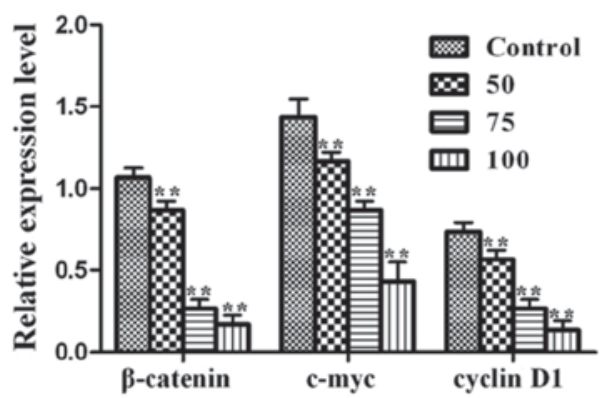

Figure 3. Resveratrol inhibits the expression level of $\beta$-catenin, c-myc, and cyclin D1 proteins in MGC-803 cells by western blot analysis. (A) $\beta$-catenin, c-myc, and cyclin D1 proteins. (B) Gray scale analysis of $\beta$-catenin, c-myc, and cyclin D1 proteins, ${ }^{* * *} \mathrm{P}<0.01$.

$\beta$-catenin correlates with the incidence of pathologies of the digestive system, hematological malignant tumors, and the reproductive system (16).

In this report, we show that resveratrol inhibits the proliferation of MGC-803 cells, induces apoptotic changes in cell morphology, and inhibits the expression of the proliferation factors $\beta$-catenin, c-myc, and cyclin D1 at the mRNA and protein levels. Utsuki et al (17) found that the expression levels of cyclin D1 and $\beta$-catenin gradually increased along with the progression of tumors. In addition, other research has found that the positive expression rate of $\beta$-catenin, c-myc, and cyclin D1 in nephroblastoma cells is significantly increased compared with normal renal tissues (18), indicating that the Wnt/ $\beta$-catenin signaling pathway plays an important role in the formation of ephroblastoma. Hu et al and Liu et al $(19,20)$ proposes that resveratrol reduces the $\beta$-catenin abnormally accumulated in HCT116 cells and inhibits the expression of cyclin D1 and c-myc, and therefore inhibits the tumor growth in colon cancer cells. This result has provided theoretical basis for the therapeutic effect of resveratrol for gastric cancer.

In conclusion, we proved that resveratrol can inhibit the proliferation of gastric cancer MGC-803 cell line, and its action mechanism may be achieved by inhibiting Wnt signal pathway.

\section{Acknowledgements}

Not applicable.

\section{Funding}

No funding was received. 


\section{Availability of data and materials}

The datasets used and/or analyzed during the current study are available from the corresponding author on reasonable request.

\section{Authors' contributions}

HD wrote the manuscript. HBD and HD were responsible for cell culture. YHW performed PCR. JJG contributed to western blot analysis. All authors read and approved the final version of the manuscript.

\section{Ethics approval and consent to participate}

The study was approved by the Ethics Committee of Changchun University of Traditional Chinese Medicine Affiliated Hospital (Changchun, China).

\section{Consent for publication}

Not applicable.

\section{Competing interests}

The authors declare that they have no competing interests.

\section{References}

1. Lv Y, Song L, Chang L, Liu Y, Zhang X, Wang Y, Wang L and Liu W: Bevacizumab followed by chemotherapy is potential therapy for gastric cancer. J BUON 21: 1466-1470, 2016.

2. Shu B, Lei S, Li F, Hua S, Chen Y and Huo Z: Laparoscopic total gastrectomy compared with open resection for gastric carcinoma: A case-matched study with long-term follow-up. J BUON 21: 101-107, 2016.

3. Shen YH, Xie ZB, Yue AM, Wei QD, Zhao HF, Yin HD, Mai W, Zhong XG and Huang SR: Expression level of microRNA-195 in the serum of patients with gastric cancer and its relationship with the clinicopathological staging of the cancer. Eur Rev Med Pharmacol Sci 20: 1283-1287, 2016.

4. Zhou SF, Yin JB, Yang H, Zhong J and An P: Application value of stomach filling ultrasonography and intravenous contrast agents in diagnosis of advanced gastric cancer. Eur Rev Med Pharmacol Sci 20: 3206-3210, 2016.

5. Zhang N, Wang AY, Wang XK, Sun XM and Xue HZ: GAS5 is downregulated in gastric cancer cells by promoter hypermethylation and regulates adriamycin sensitivity. Eur Rev Med Pharmacol Sci 20: 3199-3205, 2016.

6. Mello BS, Lucena AF, Echer IC and Luzia MF: Patients with gastric cancer submitted to gastrectomy: An integrative review. Rev Gaúcha Enferm 31: 803-811, 2010 (In Portuguese).
7. Bang YJ, Van Cutsem E, Feyereislova A, Chung HC, Shen L, Sawaki A, Lordick F, Ohtsu A, Omuro Y, Satoh T, et al: ToGA Trial Investigators: Trastuzumab in combination with chemotherapy versus chemotherapy alone for treatment of HER2-positive advanced gastric or gastro-oesophageal junction cancer (ToGA): A phase 3, open-label, randomised controlled trial. Lancet 376: 687-697, 2010.

8. Olaku O and White JD: Herbal therapy use by cancer patients: A literature review on case reports. Eur J Cancer 47: 508-514, 2011.

9. Aggarwal BB, Bhardwaj A, Aggarwal RS, Seeram NP, Shishodia S and Takada Y: Role of resveratrol in prevention and therapy of cancer: Preclinical and clinical studies. Anticancer Res 24: 2783-2840, 2004.

10. Gescher A, Steward WP and Brown K: Resveratrol in the management of human cancer: How strong is the clinical evidence? Ann N Y Acad Sci 1290: 12-20, 2013.

11. Crew KD and Neugut AI: Epidemiology of upper gastrointestinal malignancies. Semin Oncol 31: 450-464, 2004

12. Miyoshi K and Hennighausen L: Beta-catenin: A transforming actor on many stages. Breast Cancer Res 5: 63-68, 2003.

13. Maruyama K, Ochiai A, Akimoto S, Nakamura S, Baba S, Moriya Y and Hirohashi S: Cytoplasmic beta-catenin accumulation as a predictor of hematogenous metastasis in human colorectal cancer. Oncology 59: 302-309, 2000.

14. Polakis P: Wnt signaling and cancer. Genes Dev 14: 1837-1851, 2000.

15. Lim SC and Lee MS: Significance of E-cadherin/ $\beta$-catenin complex and cyclin D1 in breast cancer. Oncol Rep 9: 915-928, 2002

16. Roh MS, Hong SH, Jeong JS, Kwon HC, Kim MC, Cho SH, Yoon $\mathrm{JH}$ and Hwang $\mathrm{TH}$ : Gene expression profiling of breast cancers with emphasis of beta-catenin regulation. J Korean Med Sci 19: 275-282, 2004

17. Utsuki S, Sato Y, Oka H, Tsuchiya B, Suzuki S and Fujii K: Relationship between the expression of E-, N-cadherins and beta-catenin and tumor grade in astrocytomas. J Neurooncol 57: 187-192, 2002.

18. Ehrlich D, Bruder E, Thome MA, Gutt CN, von Knebel Doeberitz M, Niggli F, Perantoni AO and Koesters R: Nuclear accumulation of beta-catenin protein indicates activation of wnt signaling in chemically induced rat nephroblastomas. Pediatr Dev Pathol 13: 1-8, 2010.

19. Hu Y, Wang S, Wu X, Zhang J, Chen R, Chen M and Wang Y: Chinese herbal medicine-derived compounds for cancer therapy: A focus on hepatocellular carcinoma. J Ethnopharmacol 149: 601-612, 2013.

20. Liu YZ, Wu K, Huang J, Liu Y, Wang X, Meng ZJ, Yuan SX, Wang DX, Luo JY, Zuo GW, et al: The PTEN/PI3K/Akt and $\mathrm{Wnt} / \beta$-catenin signaling pathways are involved in the inhibitory effect of resveratrol on human colon cancer cell proliferation. Int J Oncol 45: 104-112, 2014.

This work is licensed under a Creative Commons Attribution-NonCommercial-NoDerivatives 4.0 International (CC BY-NC-ND 4.0) License. 